\title{
Sternotomi ile ameliyat edilen hastalarda negatif basınçlı yara kapama sistemi kullanım tecrübemiz
}

\section{Our experience of using negative pressure wound closure system in patients operated with sternotomy}

\author{
Deniz Sarp BEYAZPINAR*
}

Başkent Üniversitesi Tıp Fakültesi, Kalp Damar Cerrahisi Anabilim Dalı, Ankara/TÜRKiYE

Öz

Amaç: Sternotomi sonrası mediastinit kalp cerrahisinin önemli sorunlarında birisidir. Mediastinit gelişen hastalarda mortalite ise hatrı sayılır derecede yüksektir. Negatif basınçlı yara kapama sistemi (VAK) yüzeyel kronik yaraların tedavisi amacı ile kullanılmaktadır. Biz de sternotomi ile opere ettiğimiz ve ameliyat sonrası yara yeri enfeksiyonu gelişen hastalardaki VAK kullanım tecrübelerimi paylaşmak istedik.

Gereç ve Yöntemler: 2014 yılından itibaren açık kalp cerrahisi geçirmiş olan 2474 hasta retrospektif olarak incelenilmiştir. Yara yerinde akıntı şikayeti ile başvurmuş toplam 87 hasta çalışmaya alınmıştı. 49 hastaya açık pansuman yapılmışken, 38 hastaya VAK tedavisi uygulanmıştır.

Bulgular: VAK tedavisi uygulanılan grubun yaş ortaması 63,35 $\pm 1,15$ iken açık pansuman yapılan grupta 65,06 $\pm 2,94$ 'tur. VAK tedavisi uygulanılan grubun BMI ortaması 27,83 $\pm 4,69$ iken açık pansuman yapılan grupta 27,93 44,68'tur. Mortalite açısından iki grup karşılaştırıldığındada iki grup arasında istatistiksel fark saptanmamıştır.VAK tedavisi uygulanılan grubun hastane ortalama yatış süresi 26,33 \pm 11,67 iken açık pansuman yapılan grubunda 42,26 \pm 5,24'tur. ìki grup arasında istatistiksel olarak anlamlı fark mevcuttur (p刃0,005).

Sonuç:VAK sistemleri kalp cerrahisinin önemli bir komplikasyonu olan mediastinit tedavisinde iyi bir seçenektir. Her kliniğin uygulama yöntemleri değişik olsa dahi doğru kullanıldığında ciddi fayda gösterdiğini hem bizim hemde literatürdeki diğer çalışmalar net bir şekilde göstermiştir.

Anahtar kelimeler: VAK; sternotomi; mediastinit.

Sorumlu Yazar*: Deniz Sarp BEYAZPINAR, Başkent Üniversitesi Tıp Fakültesi, Kalp Damar Cerrahisi Anabilim Dalı, Ankara/TÜRKiYE 


\section{Abstract}

Aim: Post-sternotomy mediastinitis is one of the important problems of cardiac surgery. Mortality in patients with mediastinitis is considerably high. Negative pressure wound closure system (VAC) is used for the treatment of superficial chronic wounds. We wanted to share our experiences with VAK use in patients who were operated with sternotomy and developed postoperative wound infection.

Material and Methods: 2474 patients who had undergone open heart surgery since 2014 were analyzed retrospectively. A total of 87 patients who applied with the complaint of the wound site infection were included in the study. While 49 patients were received only open wound dressings, 38 patients were received VAC treatment.

Results: The mean age of the group treated with VAK was $63.35 \pm 1.15$, while it was $65.06 \pm 2.94$ in the open dressing group. The mean BMI of the VAC treatment group was $27.83 \pm 4.69$, while it was $27.93 \pm 4.68$ in the open dressing group. When the two groups were compared in terms of mortality, there was no statistical difference between the two groups. The mean hospital stay of the VAK group was $26.33 \pm 11.67$, while it was $42.26 \pm 5.24$ in the open dressing group. There is a statistically significant difference between the two groups ( $\mathrm{p} \otimes 0.005)$.

Conclusion: VAC systems are a good option in the treatment of mediastinitis, which is an important complication of cardiac surgery. Both our and other studies in the literature have clearly shown that even if the application methods of each clinic are different, when used correctly, it has considerable benefits.

Keywords: VAC, sternotomy; mediastinis.

\section{Giriş}

Sternotomi sonrası mediastinit kalp cerrahisinin önemli sorunlarında birisidir.[1] Literatürde farklı yazılarda \%0,510 arasında görülmektedir.[1-3] Sternotomi sonrasında gelişebilecek enfeksiyon komplikasyonlar; mediastinit, cerrahi yara yeri enfeksiyonları, osteomyelit, driveline ve cep enfeksiyonlarıdır.[2] Mediastinit gelişen hastalarda mortalite ise \%10-20 arasında olduğu saptanılmıştır.[1] Yapılan çalışmalar obezite, uzun kardiyopulmoner bypass ve ameliyat süreleri, kalp yetmezliği ve daha önceden ameliyat geçiren hastalarda daha sık görülmektedir. En sık karşılaşılan mikroorganizma ise staphilococcus şuşlarıdır.[3] Tedavide uygulanılabilecek metodlar; pansuman, antibiotik tedavisi, debridman, sternal refiksasyon, sternal rezeksiyon, kas flepleri çevrilmesi veya omentum repozisyonudur.

İlk 1997 yılında VAK sistemi yüzeyel kronik yaraların tedavisi amacı ile Argenta ve Morykwas tarafından tarif edilmiştir. [4] O zamandan beri makinaların küçülmesine bağlı olarak hastaların mobilizasyonda kolaylık sağlamakta. Bantla kapama sistemlerinin gelişmesi daha iyi yapışması sayesinde hasta eve yollanılarak ayaktan takip edilebilmektedir.[1-3]

VAK tedavisinin yara iyileşmesi üzerine olan etkileri; yara bölgesinin temiz tutulması, doku ödemini azaltma ve lokal kan akımında artış (intertsiyel basınç azalır ve kapiller kan akımında artış), enfeksiyonu yükünde azaltma, sitokinlerin, proteolitik enzimler ve akut faz reaktanlarının uzaklaştırılması ve granülasyon dokusunun oluşumunu arttırma şeklindedir.[1,2]

\section{Gereç ve Yöntemler}

2014 ylından itibaren açık kalp cerrahisi geçirmiş olan 2474 hasta retrospektif olarak incelenilmiştir. Yara yerinde akıntı şikayeti ile başvurmuş toplam 87 hasta çalışmaya alınmıştır. 49 hastaya açık pansuman yapılmışken, 38 hastaya vak tedavisi uygulanmıştır.

VAKtedavisi uygulanılan 38 hasta dahil edilmişken, açık pansuman ile tedavi edilmiş olan 49 hasta çalışmaya dahil edilmiştir. Hastaların yaş, cinsiyet, vücut kitle indeksi (BMI), daha önce açık kalp ameliyatı olup olmadığı, Preoperatif risk değerlendirmesi için kullanılan EUROSCORE değerleri, Hastane yatış süreleri ve tüm sebeplere bağlı mortalite kayıt altına alınılmıştır.

Tüm hastalara mediastinit, osteomyelit ve perikardiyal effüzyon tanısı koyulması amacı ile toraks bilgisayarlı tomografi (BT) ve ekokardiyografi (EKO) yapılmıştır. Kültürde üremesi olan hastalara etkin antibiotik tedavisi enfeksiyon hastalıkları tarafından başlanıımıştır.

Açık pansuman yapılan hastalara pansumanın kirlenmesi durumda hergün farklı sayıda pansuman yapılmış olup pansumanı kirlemeyen hastalara günde en az bir kere pansuman yapılmıştır. VAK tedavisi uygulanan hastalara ise 3 günde bir VAK pansumanı yenisi ile değiştirilmiştir. (Resim 1)

Her iki gruptada pansuman esnasında debridman gereken durumlarda debridman yapılmış olup dokudaki yabancı 
materyallerin hepsi pansuman esnasında uzaklaştırılmıştır. Hastalarda 3 günde bir kültür alınılmıştır ve 3 adet temiz kültür gelmesi durumunda yara primer olarak kapatılmıştır.

VAK tedavisi yapılan grupta erken dönemde intertsiyel ödem sebebi ile intervaller arasındaki sürede kapama sisteminin bantlarında sızıntı sebebi ile açılma olabilmektedir. Bu sebep ile erken dönemde sürekli negatif basınç kullanmaktayız. İlerleyen dönemde emme basıncını düşüyoruz.
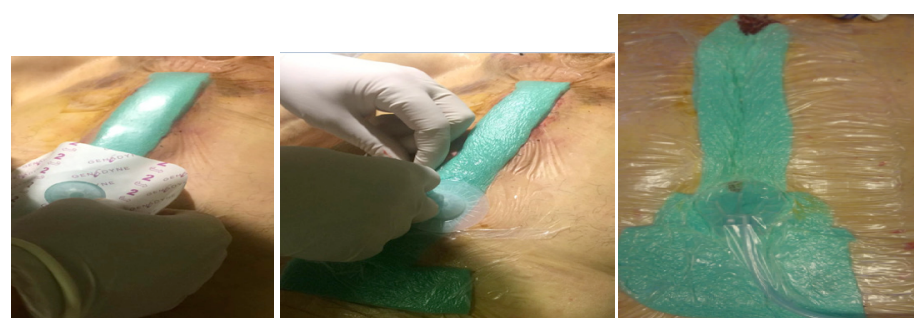

Resim 1. VAK uygulaması.

\section{İstatistiksel Analiz}

İstatistiksel analiz için SPSS versiyon 25 (SPSS, Inc, Chicago, IL) kullanılmıştır. Gruplar arasında karşılaştırılmada verilen $p$ değerleri 0,05 değerinden küçük ise anlamlı farklılık olduğu anlamına gelmektedir. Sig=p >0,05 ise farklılık yok anlamına gelmektedir. Kategorik verilerin karşılaştırılmasında MannWhitney testi kullanılmıştır.

\section{Bulgular}

İki grubun demografik verileri Tablo 1'de gösterilmiştir. VAK tedavisi uygulanılan grubun yaş ortaması 63,35 $\pm 1,15 \mathrm{iken}$ açık pansuman yapılan grupta 65,06 $\pm 2,94$ 'tur. İki grup arasında istatistiksel olarak anlamlı fark yoktur.

VAK tedavisi uygulanılan grubunda 17 bayan hasta varken, açık pansuman yapılan grupda bayan hasta sayısı 23 'tur. İki grup arasında istatistiksel olarak anlamlı fark yoktur.

VAK tedavisi uygulanılan grubun BMI ortaması 27,83 \pm 4,69 iken açık pansuman yapılan grupta $27,93 \pm 4,68$ 'tur. İki grup arasında istatistiksel olarak anlamlı fark yoktur.

VAK tedavisi uygulanılan grubunda 7 (17,94\%) hastaya daha önceden açık kalp ameliyatı geçirmişken, açık pansuman yapılan grupta bu sayı 9'dur (18,36\%). İki grup arasında istatistiksel olarak anlamlı fark yoktur.

VAK tedavisi uygulanılan grubun Euroscore ortaması 4,84 $\pm 0,56$ iken açık pansuman yapılan grupta 4,95 $\pm 0,55^{\prime}$ tır. İki grup arasında istatistiksel olarak anlamlı fark yoktur.

Herhangi bir sebebe bağlı olan mortalite açısından iki grup karşılaştırıldığında da iki grup arasında istatistiksel fark saptanmamıştır.

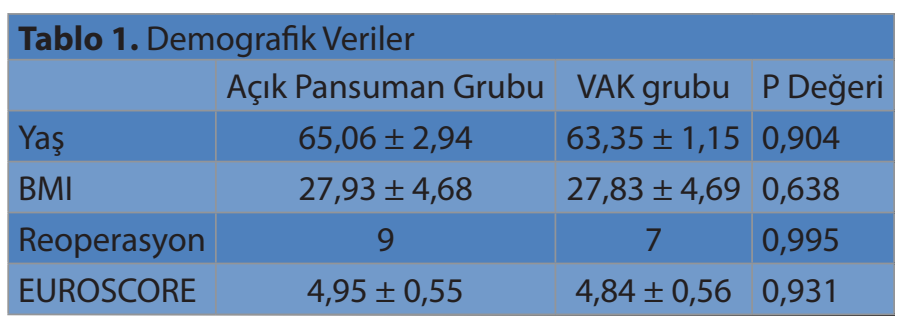

VAK tedavisi uygulanılan grubun hastane ortalama yatış süresi $26,33 \pm 11,67$ iken açık pansuman yapılan grubunda 42,26 $\pm 5,24$ 'tur. İki grup arasında istatistiksel olarak anlamlı fark mevcuttur ( $\mathrm{p} \otimes 0,005)$.

Herhangi bir nedene bağlı gelişen mortalite açısından iki grup karşılaştırıldığında iki grup arasında istatistiksel olarak fark saptanmamıştır.

Çalışma onayı üniversitemiz Klinik Araştırmalar Etik Kurulu'ndan alındı. Bu çalışma tek merkezde, retrospektif ve gözlemsel bir çalışma olarak tasarlanmıştır ve Helsinki Deklarasyonu'na uygun olarak gerçekleştirilmiştir. Hastalardan aydınlatılmış onam formu alındı.

\section{Tartışma}

Sternotomi sonra mediastinit ciddi bir komplikasyondur. Hasta hızlı ve etkin şekilde tedavi edilmez ise mortal seyredebilir. Hızlı ve etkin bir tedavi için hastanın pansumanın her zaman temiz kalması önemli bir noktadır. Fakat akıntının çok olduğu hastalarda ciddi bir iş gücü gerektirmektedir. Açık pansuman ile takip ettiğimiz hastalarda açık pansuman sıklığı değişmekle beraber günde 5-6 kereye kadar çıkabilmektedir. Buna karşılık olarak VAK sistemlerinde 3 günde 1 pansuman yapılması ciddi bir iş gücü kaybını engellemektedir. Ayrıca her pansuman esnasında bantların açılması aşamasında hasta ciddi ağrı hissetmektedir. Dolayısıyla hasta memnuniyeti açısından ciddi fayda sağlamaktadır. VAK tedavisinin en önemli avantajlarında biriside hasta yatış sürelerini kısaltarak sağlık harcamalarını azaltmasıdır.[4,5] Yapmış olduğumuz çalışmada istatistiksel olarak hastane yatış sürelerini kısalttığını gösterdik. Bu sonuç literatür ile uyumludur.

İlk kullanılmaya başladığı günden itibaren gelişen teknolojisi sayesinde VAK sistemleri daha kolay uygulanılması ve cihaz boyutlarının küçülmesine bağlı olarak hastanın daha kolay adapte olabildiği bir hal almıştır. Hastalar serviste kolaylıkla mobilize olabilmektedir.

Morykwas ve ark; ortalama $-125 \mathrm{mmHg}$ basınç uygulamasının yara bölgesi kan akımını 4 kat arttırdığını, ortalama 5-7 dk uygulama sonrası $2 \mathrm{dk}$ ara verilerek aralıklı uygulamaya devam edilmesinin ise en yüksek seviyede lokal kan akımı sağlayarak yara iyileşmesini hızlandırdığını göstermişlerdir. 
[6] Fakat intermitant kullanım erken dönemde hastanın akıntısı fazla olması durumunda VAK pansumanın açılmasına sebep olmaktadır bu sebep ile erken dönemde sürekli emme modunda ve daha yüksek basınç ile tedaviye başlayıp sonraki dönemde gelen miktarı günde 100 cc'nin altına düştüğünde -125 mmHg emme basıncı ile kullanmaktayız.

Çalışmalar göstermiştir ki sık pansuman yapılmasının ve sürekli yaranın açılarak süperenfeksiyondan korunulması, hastane yatış sürelerinin kısalması, tedavi maliyetlerini azalma, tedavi süresinde kısalma ve sternal dehissencenin eşlik ettiği enfeksiyonlar haricinde veya küçük yara yeri enfeksiyonları ve driveline enfeksiyonlarında hasta ayaktan takip edilebilir.[5,6]

\section{Sonuç}

VAK sistemleri kalp cerrahisinin önemli bir komplikasyonu olan mediastinit tedavisinde iyi bir seçenektir. Her kliniğin uygulama yöntemleri değişik olsa dahi doğru kullanıldığında ciddi fayda gösterdiğini hem bizim hemde literatürdeki diğer çalışmalar net bir şekilde göstermiştir.

\section{Çıkar çatışması / finansal destek beyanı}

$\mathrm{Bu}$ yazıdaki yazarların herhangi bir çıkar çatışması yoktur. Yazının herhangi bir finansal desteği yoktur.

\section{Kaynaklar}

1. Domkowski PW, Smith ML, Gonyon, DL, Drye C et al. Evaluation of vacuum-assisted closure in the treatment of poststernotomy mediastinitis. J Thoracic and Cardiovasc Surg 2003; 126: 386-9

2. Gummert JF, Barten MJ, Hans C et al. Mediastinitis and cardiac surgery - an updated risk factor analysis in 10,373 consecutive patients. J Thorac Cardiovasc Surg 2002; 50: 87-91.

3. Milano CA, Kesler K, Archibald N et al. Mediastinitis after coronary artery bypass graft surgery. Circulation 1995; 92: 2245-51.

4. Morykwas MJ, Argenta LC, Shelton B et al. Vacuum-assisted closure: a new method for wound control and treatment: animal studies and basic foundation. Ann Plast Surg 1997; 38: 553-62.

5. Gummert JF, Barten MJ, Hans C, et al. Mediastinitis and cardiac surgery-an updated risk factor analysis in 10,373 consecutive patients. J Thorac Cardiovasc Surg 2002; 50: 87-91.

6. Milano CA, Kesler K, Archibald N, et al. Mediastinitis after coronary artery bypass graft surgery. Circulation 1995; 92: 2245-51. 